\title{
Pivoting Strategies: A Study of Pivot Severity, Investor Reliance, and Revenue among Startups
}

\author{
Cesar Bandera \\ Martin Tuchman School of Management \\ New Jersey Institute of Technology \\ bandera@njit.edu
}

\author{
Ellen Thomas \\ Martin Tuchman School of Management \\ New Jersey Institute of Technology \\ ellen.thomas@njit.edu>
}

\begin{abstract}
"Pivoting", or a strategic shift in the direction of a venture, may be one of the most recognizable terms in entrepreneurship. Although this term has entered the entrepreneurial lexicon, very little is known about the impact pivoting has on new venture performance. Some studies suggest pivoting has positive effects on performance while others suggest executing too many pivots adversely affect it. This paper seeks to better understand the impact of multiple pivots on revenue by investigating the moderating roles of pivot severity (the degree to which a pivot represent a market shift) and reliance on investors. We investigate the impact of multiple pivots on revenue, distinguishing between high-tech vs low-tech startups and between mild vs severe pivots. We also investigate the impact that equity investments have on the pivot-revenue relationship of high-tech firms. Using change in a venture's NAICS code as a proxy for pivoting, we find an inverted- $U$ relationship between magnitude of pivots and the likelihood of revenue among Kauffman Firm Survey participants. Among high-tech firms, this relationship differs based on the firm's reliance on investors. This longitudinal empirical study on the relationship between pivot magnitude, investor reliance, and revenue aims to attract attention to this important topic of entrepreneurship, and help the entrepreneur facing the difficult decision of whether or not to pivot.
\end{abstract}

\section{Introduction}

In the face of unexpected events, entrepreneurs must decide whether to persevere with their original idea or pivot away from it. Those events can either be the belief that the existing business model is not viable, for example problems in the development process $[1,2]$ or the perception of new opportunities and possibilities for expansion [3].
The term "pivot" was first coined by Eric Ries in 2009 [4] and defined as "a structured course correction designed to test a new fundamental hypothesis" [2] (pg 149) explaining that "we keep one foot rooted in what we've learned so far, while making a fundamental change in strategy in order to seek greater validated learning" (pg 154). The term is now part of the everyday language of entrepreneurs and those who advise and fund them.

While some think of a pivot as "an especially radical type of organizational change for new ventures" [5] (pg 3 ), the degree to which a pivot changes a business model can fall anywhere within a wide range of severity. At one end, entrepreneurs conduct validated learning incrementally by varying slightly a single element of their business model. Alternatively, entrepreneurs can make a radical change to their strategy, such as changing multiple elements of their business model $[3,6]$ or pivoting to a radically different market. The decision to continue with the current strategy or pivot away from it is one of the hardest that entrepreneurs face [2].

The entrepreneurship literature promotes and celebrates pivoting with anecdotes of successful pivots, treating strategic change as an appropriate move and assuming it was a correct and necessary decision [3]. For example, Groupon began as a do-good site called The Point, PayPal started as cryptography libraries for Palm Pilot devices, YouTube started as a video-dating site, and Twitter began as a platform to subscribe to podcasts [7].

There are many reasons an entrepreneur would decide to pivot. Staying with a business idea that is not working could have severe consequences particularly for a start-up, which is often focused on a single project. Questioning and refining underperforming business models helps entrepreneurs discover and assess alternatives, empirically gather valuable market information, and make better strategic decisions [8]. Failure followed by pivoting is often considered a validated learning process [2, 4]. Research has also found that business model viability is greatly improved 
by business model experimentation. For example, pivoting is the most frequently occurring commonality among different successful startups [2] and committing too early to a specific business model can have negative effects on long-term survival and performance [6]. Furthermore, most pivots are reactions to external, rather than internal events, such as negative customer reactions to the initial product, an inability to survive competition, technology issues, and positive responses from an unforeseen customer segment [1].

However, pivoting is not a guarantee for success. One core problem inherent in changing direction is it can consume resources and move entrepreneurs away from competencies. As entrepreneurs build their businesses, they become increasingly knowledgeable in the associated processes, technologies and markets. This tacit knowledge may become irrelevant when pivoting severely, resulting in lost time and resources [9]. Another core problem is that while firms may need to radically change direction in order to survive, doing so risks alienating stakeholders that had helped sustain the firm up to that point [5], including investors, employees, and partners.

Entrepreneurs therefore should be mindful of the frequency and severity of their pivots. Ladd [10] found that while ventures that tested hypotheses performed better than those that did not, there was no relationship between the number of validated hypotheses and a venture's subsequent success (i.e., more pivots are not necessarily better) and that a consistent strategy might appeal to investors better than continuous market tests.

Currently there is a gap in the understanding of the consequences of pivoting, which deserves attention for researchers and practitioners alike. Prior work tends to be conceptual [11-13], qualitative [3, 6, 14], or quantitative in the context of established firms $[15,16]$. Research on startup pivots tends to focus on antecedents, i.e. what triggers a pivot, such as feedback, environmental factors, entrepreneur characteristics, or investment $[1,9,17]$. For example, the willingness of founders to change their ideas in response to feedback may depend in part on their "psychological ownership" of those ideas, meaning the degree to which those ideas are seen as extensions of themselves [18]. Entrepreneurs who focus on the exploitation of new opportunities tend to be flexible and responsive to new information, while entrepreneurs who focus on innovation through novel ventures tend to reject any change that could undermine venture novelty [19]. Additionally, entrepreneurs who are reliant on investors may find it more difficult to pivot [9].

In general, existing research and knowledge on pivots is limited and there has been a call for better understanding of its impact in new ventures $[1,3,8]$.
This study helps fill the research gap in a number of ways. First, we use the Kauffman Firm Survey longitudinal dataset to empirically investigate the relationship between the likelihood of startup success and its pivot activity. Second, recent studies of pivot activities $[1,17]$ noted that firms usually engage in multiple pivots. However, multiple pivots do not always lead to revenue and can result in an inverted-U relationship with the likelihood of success $[10,20]$. This study looks to advance our understanding of pivots by investigating pivot severity. Does the impact of multiple pivots on likelihood of startup success differ by the severity of the pivots? Does this impact differ between high-tech and low-tech startups? Furthermore, in the context of high-tech firms, this study also investigates the moderating role of investor reliance.

Entrepreneurs need to persevere when facing adversity and skepticism. However they must also be flexible enough to leave behind some of the ideas in which they invested, and explore different opportunities [9]. To the best of the authors' knowledge, this study is the first of its kind to address the issue of the likelihood of pivoting success with respect to pivot severity, firm type, and investor reliance.

\section{Framework and Hypotheses}

Pivots have been defined as "course changes", "strategy shifts", or "business model adaptations". A pivot is often considered as an experiment to validate a business model hypothesis [2, 21] and the path entrepreneurs must take when looking for the correct strategy. In other words, a pivot is often synonymous with change. Startups can make different types of pivots such as changes to the product/service, target customer segment, business architecture, value proposition, engine of growth, channel, and technology [2].

Some pivots are considered incremental where a small element of the product, service, or business model is changed, or simple elements are added or dropped from an existing strategy. Other pivots can be significant and change multiple elements of the business model or completely reorganize the current strategy [3, 6]. Startups typically make a series of small pivots to reach a successful strategy, commonly defined as one that achieves revenue $[3,17,22]$ (a venture usually does not achieve profit, which is more desirable than revenue, until its growth phase that follows the startup phase). Startups undergo an average of five pivots during their development [17].

The term "pivot" has become so ubiquitous that even the popular press is criticizing using the word to mean almost anything [23], writing that "100 microadjustments to business models" is smart management, 
not pivoting. Literature has also questioned when does change become a pivot [3]. Thus, any in-depth analysis of pivoting should consider both the number of pivots executed by a venture, and the severity of these pivots.

This study investigates pivots that are significant enough to cause a change in the startup's North American Industry Classification System (NAICS) code. The NAICS code of a firm reflects the firm's value proposition, i.e., what it offers and to whom. Thus, a pivot that significantly changes a firm's product, service, or target market (e.g., wholesale or retail) will also change the firm's NAICS code.

The hierarchy of the six-digit NAICS code lends itself to a measurement of pivot severity; the two most significant (i.e., leftmost) digits of a firm represent the firm's sector, and each subsequent digit identifies a smaller sector subset in which the firm operates. The smallest measureable pivot would change the least significant (i.e., rightmost) digit whereas more severe pivots would change a more significant digit, and the most severe pivot would change the most significant digit. We can thus quantify the severity of a pivot as the position of the most significant NAICS digit changed by the pivot, i.e., the number of digits in the difference between the NAICS code before and after the pivot.

While pivoting can improve a startup's strategy, pivoting too frequently and/or too severely can defeat it. This study looks at the relationship between startup success (revenue) and pivoting behavior, accounting for both the number and severity of pivots by using the concept of cumulative pivot severity, which is the running sum of the severity of all the pivots executed by a venture since its inception. Therefore, we hypothesize:

H1: The likelihood of revenue for a startup exhibits an inverted-U relationship with its cumulative pivot severity.

Most High-tech firms operate in greater market uncertainty than low-tech firms because the formers' business models tend to be more innovative. High-tech firms may therefore benefit more from the business model validation offered by pivoting. Moreover, frequent testing, tweaking and pivoting may be viable for digital and virtual assets (e.g., websites and apps), but not for traditional manufactured goods. Because, high-tech companies might need and tolerate more severe pivoting than low-tech companies, we hypothesize:

H2: The relationship between a startup's probability of revenue and cumulative pivot severity is different for high-tech and low-tech firms
It remains unclear how free ventures are to follow a radically new direction if investors oppose the new strategy. One advantage of equity funding is that there is no obligation to repay the money thereby not adding to the financial burden of the company. However, a disadvantage of equity funding is that investors have to be consulted on strategic decisions. When a pivot is looming, investors are more likely to intervene.

Entrepreneurs' commitments to investors can lead to a "fixation" to ideas that reduces the flexibility required to pivot [9]. Investors are not always supportive of continued change and refrain from injecting large amounts of capital until progress has been made. Successive radical pivots can weaken investor commitment because they begin to question whether the business model was wrong, if a problem lies with the entrepreneurs [24], or if pivots are the onset of mission drift [18].

Finally, the level of resources an entrepreneur has impacts the likelihood that a firm will pivot. Continually changing direction demands renewed resources and entrepreneurs may have to commit to one strategy or another. At the same time, while constrained resources may prevent entrepreneurs from effectively pivoting, too many resources might reduce the need to pivot. "A tendency to continue with the venture in its current form might only be overcome when it is clear that venture is unsustainable. Entrepreneurs seldom pivot just because of new opportunities, but because of constraints and an inability to satisfy those constraints without initiating change. These constraints might require entrepreneurs to proceed to the next funding cycle or demonstrate market demand to investors." [9] (pg 59)

Without these constraints pivots are less likely and initial ideas can be pursued for longer. An entrepreneur interviewee stated "... whenever you're living on someone else's money and there's no criteria for 'live or die' it's just easy. I've seen it [...] where the government has put so much money in technology companies to fund the risk that they [the government] don't have the confidence to say 'show us purchase orders.' So the entrepreneur's not forced to pivot." [9] (pg 59).

Given the above arguments, we hypothesized that:

H3: The relationship between likelihood of revenue and cumulative pivot severity is different between high-tech firms that rely on investor funding and those that do not.

\section{Data and Methods}

This study uses the Kauffman Firm Survey (KFS) of 4928 companies founded in 2004 and surveyed annually from 2004 to 2011 [25]. The KFS collects information 
about each participating firm's business characteristics, strategy and innovation, business organization and human resource benefits, business finances, work behavior, and ownership and demographics of its active owner and operators. Specifically, the study uses the confidential longitudinal long-format KFS dataset (KFS8_L_L1) hosted by the National Opinion Research Center (NORC) Data Enclave for the Kauffman Foundation [26]. Unlike the public version of the KFS which provides only the most significant two digits of each firm's NAICS code, the confidential dataset provides all six digits, enabling the study to detect more subtle pivots that only impact the less significant digits.

Because the KFS collects data once a year, we can detect one change annually in a firm's NAICS code. The KFS also reports for each year if each surviving participant received any revenue, considered itself a high-tech firm or not, and if it received any form of equity investment. Not all ventures survive each year, leaving the study with 18,286 records, each one representing a year of a surviving venture.

We compute the severity of each pivot $s_{i j}$ as the number of digits in the difference between the NAICS code reported by venture $i$ in years $j$ and $j-1$. From these pivot severity values, we compute the cumulative pivot severity of venture $i$ at year $t$ as running sum

$$
c_{i}(t)=\sum_{j=2005}^{t} s_{i j} .
$$

To test $H 1$, we model the binary variable revenue $r(t)$ as a second order logistic regression of $c(t)$ and $c^{2}(t)$ and test for the statistical significance of the second-order term, which needs to negative for an inverted-U relationship. To test $H 2$, we add the binary variable $h_{i j}$ ( $0=$ venture $i$ is not a high-tech venture in year $j, 1=$ yes) and its interactions with $c(t)$ and $c^{2}(t)$ to the $H 1$ logistic regression model, and test for the statistical significance of the interaction terms. To test $H 3$, we add the binary variable $e_{i j}(0=$ venture $i$ did not rely on equity investment in year $j, 1=$ yes) and its interactions with $c(t)$ and $c^{2}(t)$ to the $H 1$ logistic regression model, and test among high-tech ventures for the statistical significance of the interaction terms.

\section{Results}

Within the 18,286 records, we detected 1725 NAICS code changes, with a distribution biased towards severe pivots (Table 1). Over $90 \%$ of the venture-years exhibited no changes to the NAICS code. The cumulative pivot severity ranged from zero to 30 .
Table 1. Distribution of pivot severity across all startups and years of survival.

\begin{tabular}{|c|c|c|c|}
\hline Severity & \multicolumn{2}{|c|}{ Count } & \\
\hline 0 & 16561 & $90.6 \%$ & \\
\hline 1 & 85 & $0.5 \%$ & $\uparrow$ \\
\hline 2 & 137 & $0.7 \%$ & 点 \\
\hline 3 & 237 & $1.3 \%$ & $\frac{0}{2}$ \\
\hline 4 & 155 & $0.8 \%$ & $\stackrel{\sim}{N}$ \\
\hline 5 & 470 & $2.6 \%$ & ㄱ. \\
\hline 6 & 641 & $3.5 \%$ & $\downarrow$ \\
\hline Total: & 18286 & $100 \%$ & \\
\hline
\end{tabular}

The second order coefficient in the logistic regression of cumulative pivot severity on revenue is negative and statistically significant ("All Firms" column in Table 2), confirming H1. The revenue odds ratio is maximum at a cumulative pivot severity of 13 (green curve in Figure 1).

Table 2. First and second order coefficients of cumulative pivot severity regression on revenue.

$$
\begin{array}{c|c|c|c} 
& \text { All Firms } & \text { Low Tech } & \text { High Tech } \\
c(t) & 0.0569 * * * & 0.0505^{* * *} & 0.0903^{*} \\
c^{2}(t) & -0.0022^{* *} & -0.0013 \text { (NS) } & -0.0072^{* * *} \\
\\
{ }^{*} \mathrm{p}<0.01, * * \mathrm{p}<0.005, * * * \mathrm{p}<0.001, \mathrm{NS}=\text { Not significant. }
\end{array}
$$

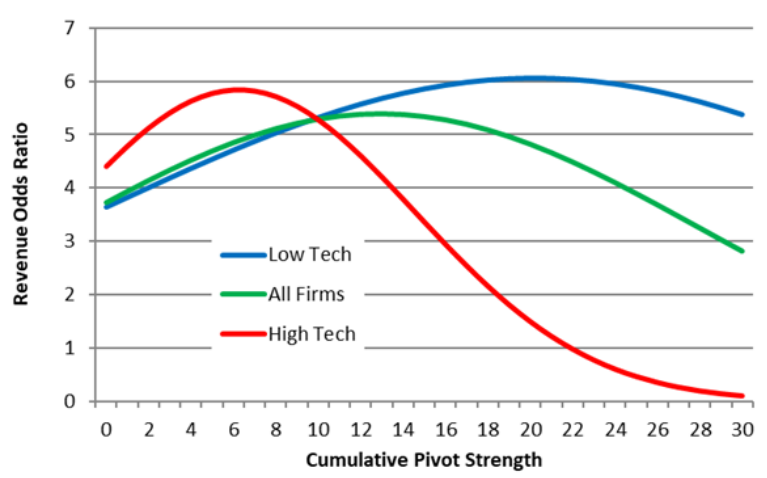

Figure 1. Revenue odds ratio versus cumulative pivot severity (high vs low tech).

Adding $h_{i j}$ to the model yields a statistically significant interaction $(\mathrm{p}<0.01)$ between the high-tech designation and the second order term $c^{2}(t)$. For both low-tech and high-tech ventures, the relationship between revenue and cumulative pivot severity is an inverted-U ("Low Tech" and "High Tech" columns in Table 2), but the optimum pivoting behaviors are different. A small amount of pivoting helps tech 
startups achieve revenue more than low-tech startups (the red curve in Figure 1 goes up steeply), but too many or too large pivots penalizes tech startups severely (the red curve plummets). In contrast, the optimum pivoting behavior for low-tech firms involves more severe pivoting (blue curve in Figure 1), but the benefits of pivoting and the penalty for over-pivoting are not as drastic (the blue curve in Figure 1 is flatter than the red curve). $H 2$ is thus confirmed.

A regression of $e_{i j}, c(t)$ and $c^{2}(t)$ with interaction terms on revenue yields a statistically significant interaction $(\mathrm{p}<0.05)$ between equity investments and the second order term $c^{2}(t)$. The optimal cumulative pivot severity for startups with equity is similar to that of firms without equity (red vs blue curves in Figure 2), but the consequences of under-pivoting or over-pivoting, and the overall likelihood of revenue, is lower for ventures with equity investments. $H 3$ is thus confirmed.

Table 3. First and second order coefficients of cumulative pivot severity regression on revenue.
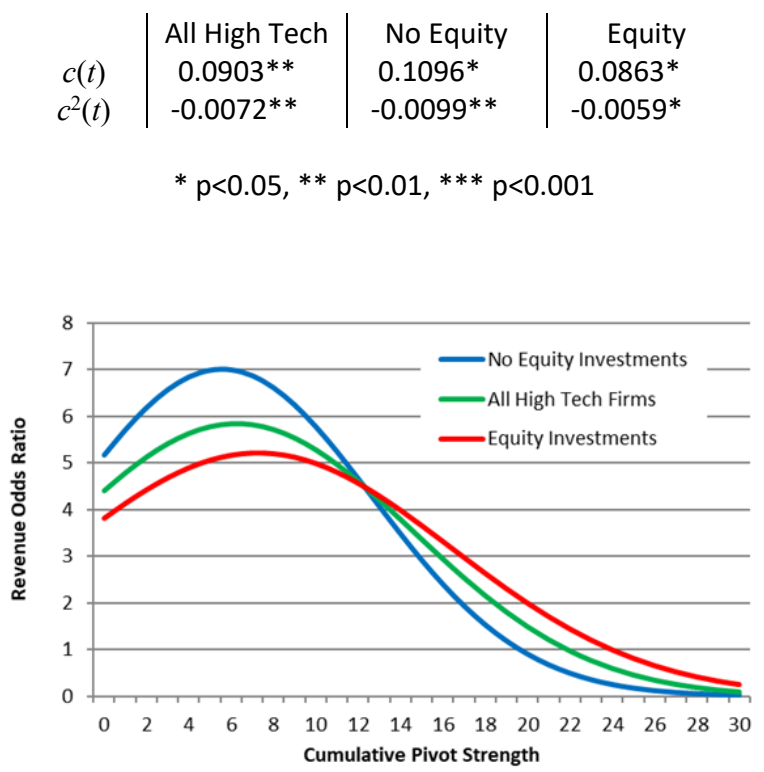

Figure 2. Revenue odds ratio versus cumulative pivot severity (equity vs no equity investments).

\section{Discussion, Limitations, and Future Research}

Startups make assumptions about the unknown that generally turn out wrong, and "new ventures inevitably experience deviations - often huge ones - from their original planned targets. Indeed, new ventures frequently require fundamental redirection" [27]. This study investigates the impact of the magnitude of the "often huge" deviations on the likelihood of revenue. We also identify a potential hazard for new ventures that rely on external funding; pivoting in this situation is far from a "cost free" strategic option, as is often portrayed in the emerging literature.

The study confirms the three proposed hypotheses, but the last two in counterintuitive ways. In $H 2$, we confirm a difference between the inverted-U curves of high-tech and low-tech revenue likelihood as a function of pivoting. This difference, however, was not as expected. We argued that because business model uncertainty is more prevalent in high-tech ventures than in low-tech ventures, the former would need more pivoting. Instead, we find that high-tech ventures are best served by a pivoting strategy with smaller cumulative severity.

In $H 3$, we confirm that equity influences the inverted-U curves of high-tech revenue likelihood as a function of pivoting. However, we expected equity investors to penalize high-tech ventures for overzealous pivoting and shy away from additional investment in the immediate aftermath of a pivot [28]. Instead, we find that equity investment flattens the inverted- $U$ curve altogether, while high-tech ventures without investors have more to gain by pivoting and more to lose from overzealous pivoting.

There are several limitations to this study. The first is that the KFS does not reveal multiple pivots that may have occurred between annual follow-ups, but only if there is a year-to-year difference in NAICS code. Second, the model presented in this paper does not differentiate between a pivot executed shortly after venture formation from a pivot executed later (e.g. 2005 vs. 2010); both contribute equally to the cumulative pivot severity, but one would expect strategic benefit to executing swiftly.

We show that the impact of pivoting on the likelihood of revenue is significant in both the practical and statistical sense. However, we also propose to the entrepreneurship research community that a better understanding of the dynamics of pivoting are required before we can provide actionable guidance to the entrepreneur facing the difficult decision of whether or not to pivot.

\section{References}

1. Bajwa, S.S., et al., "Failures" to be celebrated: an analysis of major pivots of software startups. Empirical Software Engineering, 2017. 22(5): p. 2373-2408.

2. Ries, E., The lean startup: How today's entrepreneurs use continuous innovation to create radically successful businesses. 2011: Crown Books. 
3. Kirtley, J. and S. O'Mahony, What is a pivot? Explaining when and how entrepreneurial firms decide to make strategic change and pivot. Strategic Management Journal, 2020: p. 1-34.

4. Ries, E., Lessons learned: Pivot, don't jump to a new vision. 2009.

5. Christian Hampel, P.T., Klaus Weber, The art of the pivot: How new ventures manage identification relationships with stakeholders as they change direction. Academy of Management Journal, 2020. 63(2): p. 440-471.

6. Andries, P., K. Debackere, and B. Looy, Simultaneous experimentation as a learning strategy: Business model development under uncertainty. Strategic Entrepreneurship Journal, 2013. 7(4): p. 288-310.

7. Arteaga, R., \& Hyland, J., Pivot: How top entrepreneurs adapt and change course to find ultimate success. 2013: John Wiley \& Sons.

8. Leatherbee, M. and R. Katila. Stay the Course or Pivot? Antecedents of Cognitive Refinements of Business Models in Young Firms. in Academy of Management Proceedings. 2017. Academy of Management Briarcliff Manor, NY 10510.

9. Crilly, N., 'Fixation'and 'the pivot': balancing persistence with flexibility in design and entrepreneurship. International Journal of Design Creativity and Innovation, 2018. 6(1-2): p. 52-65.

10. Ladd, T., The Limits of the Lean Startup Method. Harvard business review, 2016. 94(3).

11. McGrath, R.G., Business models: A discovery driven approach. Long range planning, 2010. 43(2-3): p. 247261.

12. Snihur, Y., B.S. Reiche, and E. Quintane, Sustaining Actor Engagement During the Opportunity Development Process. Strategic Entrepreneurship Journal, 2017. 11(1): p. 1-17.

13. Chesbrough, H., Business model innovation: opportunities and barriers. Long range planning, 2010. 43(2-3): p. 354 363.

14. Amit, R. and C. Zott, Value creation in e-business. Strategic management journal, 2001. 22(6-7): p. 493-520.

15. Kim, S.K. and S. Min, Business model innovation performance: When does adding a new business model benefit an incumbent? Strategic Entrepreneurship Journal, 2015. 9(1): p. 34-57.

16. Osiyevskyy, O. and J. Dewald, Explorative versus exploitative business model change: the cognitive antecedents of firm-level responses to disruptive innovation. Strategic Entrepreneurship Journal, 2015. 9(1): p. 58-78.

17. Brush, C.G., L.F. Edelman, and T.S. Manolova, To Pivot or Not To Pivot: Why Do Nascent Ventures Change Their Business Models? Frontiers of Entrepreneurship Research, 2015. 35(1).

18. Grimes, M., The Pivot: How Founders Respond To Feedback through Idea and Identity Work. Academy of Management Journal, 2017. in press p. amj. 2015.0823.

19. Tiona Zuzul, T., Mary Tripsas, Start-up inertia versus flexibility: The role of founder identity in a nascent industry. Administrative Science Quarterly. 65(2): p. 395433.
20. Bandera, C. and E. Thomas. To pivot or not to pivot: On the relationship between pivots and revenue among startups. in Proceedings of the 52nd Hawaii International Conference on System Sciences. 2019.

21. Blank, S., Why the lean start-up changes everything. Harvard business review, 2013.91(5): p. 63-72.

22. Hirvikoski, K. Startups pivoting towards value. Data and value-driven software engineering with deep customer insight. in Proceedings of the seminar. 2014.

23. Lamm, B., Can We Stop Pivoting Already? Odds are if you need to 'pivot,' either you made a major miscalculation or you're just growing and adapting, not pivoting, in Entrepreneur 2018.

24. Bhide, A., Bootstrap Finance: the art of start-ups. Harvard business review, 1992. 70(6): p. 109-117.

25. Robb, A. and J. Farhat, An Overview of the Kauffman Firm Survey: Results from 2011 Business Activities. 2013, Ewing Marion Kauffman Foundation.

26. Farhat, J.B. and A. Robb, Applied Survey Data Analysis Using Stata: The Kauffman Firm Survey Data. Available at SSRN 2477217, 2014

27. RG McGrath, I.M., Discovery driven planning. Harvard business review 1995. 73(July/August): p. 44-54.

28. Cottle, G.W., Capturing the Strategic Pivot: Identifying the Performance Outcomes of New Venture Pivots. 2020, University of Missouri-Kansas City. 